\title{
Transformation and Modification of Historical Building Use, and Owner Motivation for Urban Conservation in the Nineizaka and Sanneizaka Preservation District, Kyoto, Japan
}

\author{
By Naphasinee Suebsuk ${ }^{*}$ \\ Osamu Nakagawa ${ }^{\dagger}$
}

\begin{abstract}
This paper is a study of the relationship between changes in building use from the aspect of the user in the Nineizaka and Sanneizaka Preservation District for historical buildings in Kyoto. Based on a field survey study in 2013 and a detailed map produced in 1977, 1999, and 2013; this study analyses the change of building use and user modifications for urban conservation in Japan. The results show that most of the buildings in the Nineizaka and Sanneizaka Preservation District have changed. They have been transformed from shop-houses (Machiya) and dwelling houses in the past to become fully functional commercial stores. Only the traditional facade was restored after the area was designated as the first preservation district in 1976. The traditional characteristics of the buildings and environment attract a large number of tourists, creating an impact on the traditional site. Motivational factors, from user scale to community (village) scale using sustainable tourism concepts are presented through the cultural conservation of traditional building design, assisted by a budget from the government. On the other hand, many changes were discovered in the building spaces, cultural activities, traditional celebrations, and the local way of life in the area.
\end{abstract}

\section{Introduction}

Many people are interested in the past, one way or another. Once, it used to be mainly academics but nowadays interest comes from all sides. Exploring the past in its various forms can be used to point out that the popular past is really the product of another world, with its epochs and economics and not merely history controlled by academics. Tourism is used as a great promoter of the past. It also plays an important role in Kyoto.

Kyoto is surrounded by mountains on three sides. The area closest to down town in the east is called Higashiyama (Eastern Hill). This area is rich in

${ }^{*}$ PhD Student, Kyoto Institute of Technology, Japan.

†Professor, Kyoto Institute of Technology, Japan. 
Buddhist temples and Shinto shrines; a famous route for religious travellers and merchants since ancient times (Tabi no bunka or the culture of travel ${ }^{1}$ ). The sacred precincts themselves and their lengthy linear access ways, very much determine the original urban structure and historic development of the area which has now become a preservation district.

Nineizaka and Sanneizaka, located at the slope of Higashiyama Hill, are surrounded by some of Kyoto's most famous sights, including the Kiyomizudera Temple, Kodaiji Temple, and Yasaka-jinja Shrine. There are many Kyotoishness (Kyotorashisa) shops in this area of town. On both sides of its winding and sloping paths, there are places to eat, lodgings, and recreation facilities, as well as shops in which to buy various utensils used for religious worship. From the Edo period (1603-1867) onwards, it became famous as the origin of well-known types of pottery. By literary association with old poet laureates and the establishment of over two hundred years of peace during the Edo period meant more and more traditional Kyo-machiya (traditional townhouse of Kyoto) were built here. Thus, the area became a desirable residential sanctuary too.

Since the beginning of the 1970s, the value concept has been actively widened to include urban quarters or groups of traditional buildings and streetscapes found in the fabric of the buildings. This development followed a general evolution in the international conservation movement. Thus, in the United Kingdom, the Civic Amenities Act 1967 legalised the "group value" of buildings and acknowledged the importance of area conservation. In 1972, the Sanneizaka and Nineizaka area (known also as Sannenzaka and Ninenzaka) at the foot of the Higashiyama, was nominated as the first historic preservation district in Kyoto. This fine group of traditional wooden-frame buildings is part of the traditional pilgrim route to the Kiyomizu temple. It was the first urban area in Japan to be preserved by law. In 1975, historic districts or rows of traditional townhouses became eligible for subsidised protection under a national law that defined groups of historic buildings as a new type of cultural property. These areas are known in Japan as nationally important preservation areas, consisting of groups of traditional buildings, kuni no ju, yo na dentoteki kenzobutsugun hozon chiku (the preservation district for groups of historic buildings). (Salastie, 1989). In 1979, because of its active role in urban preservation, Kyoto was granted an award from the Institute of Japanese Architects for its pioneering work in urban conservation. At the beginning of the 1990s, the historic preservation areas were further extended to include a

\footnotetext{
${ }^{1}$ Tabi no bunka (旅の文化) meaning "the culture of Japanese travel"was widely used for a journey in ancient time, from its domestic travelling by foot, beginnings as religious pilgrimage, to become the leisure and recreation travel culture in the modern era until now. "History of Travelling in Japan can be found many hundreds of years ago; since the Edo period. Most revolve around religion (commercial) and religious affairs. Buddhism established itself in Japan in the seventh and eighth centuries; religion providing both the objective and means of travel. By the tenth century, both temples and Shinto shrines were making travel arrangements for sect members to visit their sanctuaries." (Graburn, 1995).
} 
number of new preservation areas following the Sanneizaka and Nineizaka model.

As the first role model of a preservation district for a group of historical buildings, the Sanneizaka and Nineizaka area was chosen in this paper for a case study to clarify the spatial and social impact created by it being under the control of the preservation of historical building regulations since 1976 and the transformation and modification of building use and owner motivation in the context of urban conservation and sustainable tourism.

\section{Scope of the Study, Research Objective and Methodology}

The scope of the study focuses on the idea of urban heritage conservation and sustainable infrastructure development to provide an overall image of its rehabilitation. The survey and study focuses on shop houses (Machiya) and historical building use in the Sanneizaka and Nineizaka Preservation District, located at the main route of the tourism site (Figure 1).

Figure 1. Scope of the Study in the Ninenzaka and Sanneizaka Area (Ninenzaka and Sannenzaka)

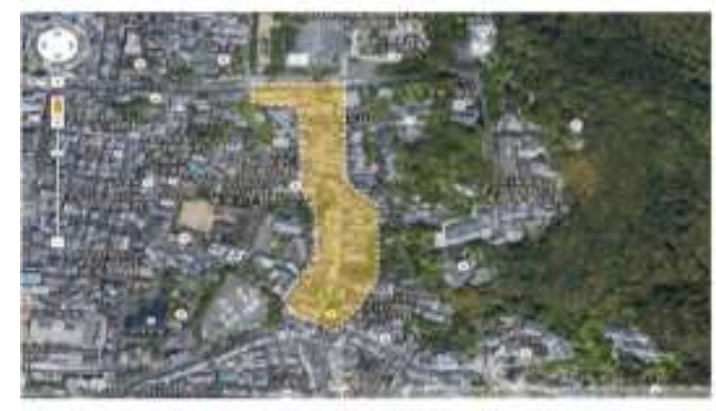

Source: Google Map, September 2013.

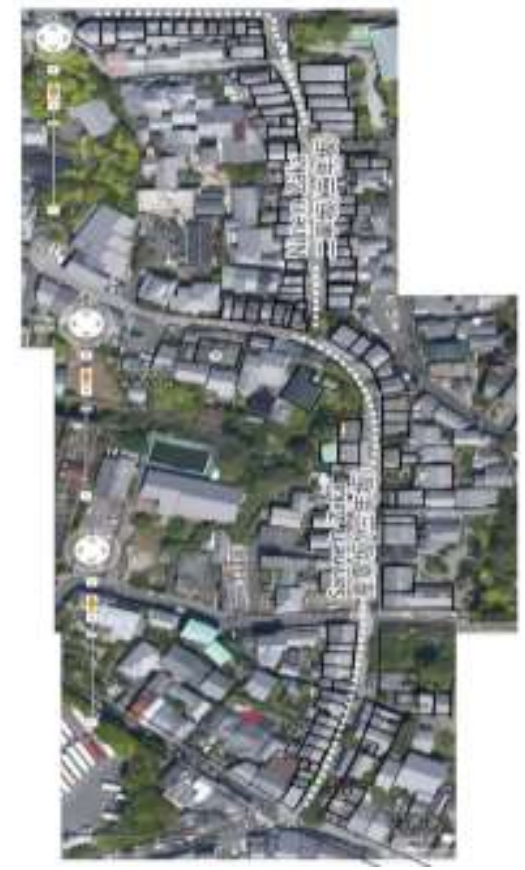

The proposed objective was to analyse the approach through the idea of conserving historical buildings in the Sanneizaka and Nineizaka Preservation District in Kyoto and how to promote and retain their identity with the changing times. Clarification and categorization of the transformation and modification of building use in the area after it was nominated in the Group of Historical Buildings as a Preservation District in 1976. The study is based on a 
field survey at the present time (2014) and a detailed map from 1977-1999. Hongii and Junzo (Hongii and Junzo, 2001).

Finally, to find a key factor "change" and its transformation including owner motivation for urban conservation on historical buildings in the area with regard to sustainable tourism.

The concept of urban conservation design and sustainable development was used as a guideline for data collection in this study. Simply defined, urban design is the composition of architectural form and open space in a community context. The elements of a city's architecture are its buildings, urban landscape, and service infrastructure -just as form, structure, and internal space are elements of a building. Whether in public or private ownership, urban design comprises the architecture of an entire community that all citizens can enjoy and identify by themselves. Like architecture, urban design reflects the considerations of function, economics, and efficiency, as well as aesthetic and cultural qualities (Barnett, 1974)

The research is based on both qualitative and quantitative methods of participant observation, using on-site surveys and questionnaires for the analysis and examination to find physical changes over time and key motivational factors of the historical building user. There are three steps to the methodology process: data collection, analysis and synthesis. The coding analysis of fieldwork data draws its formation from the transformation process of the structure in the urban conservation site management model for the sustainable traditional town in the context of urban conservation tourism.

\section{Data Collection}

\section{The Characteristics of Historical Buildings in Kyoto - Kyo Machiya}

Kyoto City has a unique climate, cold in the winter and extremely hot and humid in the summer. Kyo Machiya, the traditional townhouses of Kyoto, were designed and built to adapt to Kyoto's extreme climate and changing conditions of the seasons. In the olden days, most of the Machiya were merchants or craftsmen, building the entire structure in natural materials: wood for pillars, paper for the sliding doors, and mud for the walls. The building served for both business and living space. The front area is called "mise no mae" and is used for business. The entrance allows for separate access to the business and private living spaces of the house. In a single Machiya, both the business and living areas exist side by side while at the same time are entirely separate.

The number of Machiya is decreasing year by year due to ageing of the buildings, changing way of life, expensive maintenance costs for owners, and strict disaster and fire prevention regulations. From the survey conducted in 2003, about 13\% of Machiya were destroyed between 1996 and 2003 and over $40 \%$ of demolished Machiya sites are used for new style residential buildings. Another $40 \%$ are used for high-rise apartments, commercial buildings and car parks (Kyoto Center for Community Collaboration, 2009). Over 80\% of 
existing Machiya have lost some aspect of their original traditional structure, and the Machiya Machizukuri Fund was set up to protect the history and culture of Kyoto. Since it was set up in 2004, donations to the Fund have been invested and used to protect and promote the Machiya culture.

There are differences between certain groups of historic buildings in the special Preservation District of Sanneizaka and Nineizaka. With regulation controls on the Kyoto framework of the Kyoto City Landscape Policy, the city of Kyoto instituted a form of mutual consultation, architectural guidance, and financial support if during the project an owner asked for a building, rebuilding or repair permit. Therefore, the renewal and visual restoration (Figure 2) of the area would progress at a speed determined by the actual owners themselves. It was accepted that the preservation of this townscape did not have to mean simply protecting or retaining the same historic architecture. On the contrary, it was intended to be used as a positive planning tool, intimately related to the economic development of the district. In the past, in big Japanese cities, rebuilding of townhouses after a major fire was undertaken while respecting the overall regional architectural characteristics, social class distinctions, and available technical skills. Builders also worked only within the framework of the clear characteristics of a commonly accepted structural plan and façade element. At present, the regulations control only the façades, outdoor elements of the buildings, and streets of historical buildings in the Sanneizaka and Nineizaka area to retain the image of the townscape. The various styles of building interiors have been decorated and restored mostly for commercial proposes.

Figure 2. Building in the Nineizaka and Sanneizaka area (Ninenzaka and Sannenzaka)

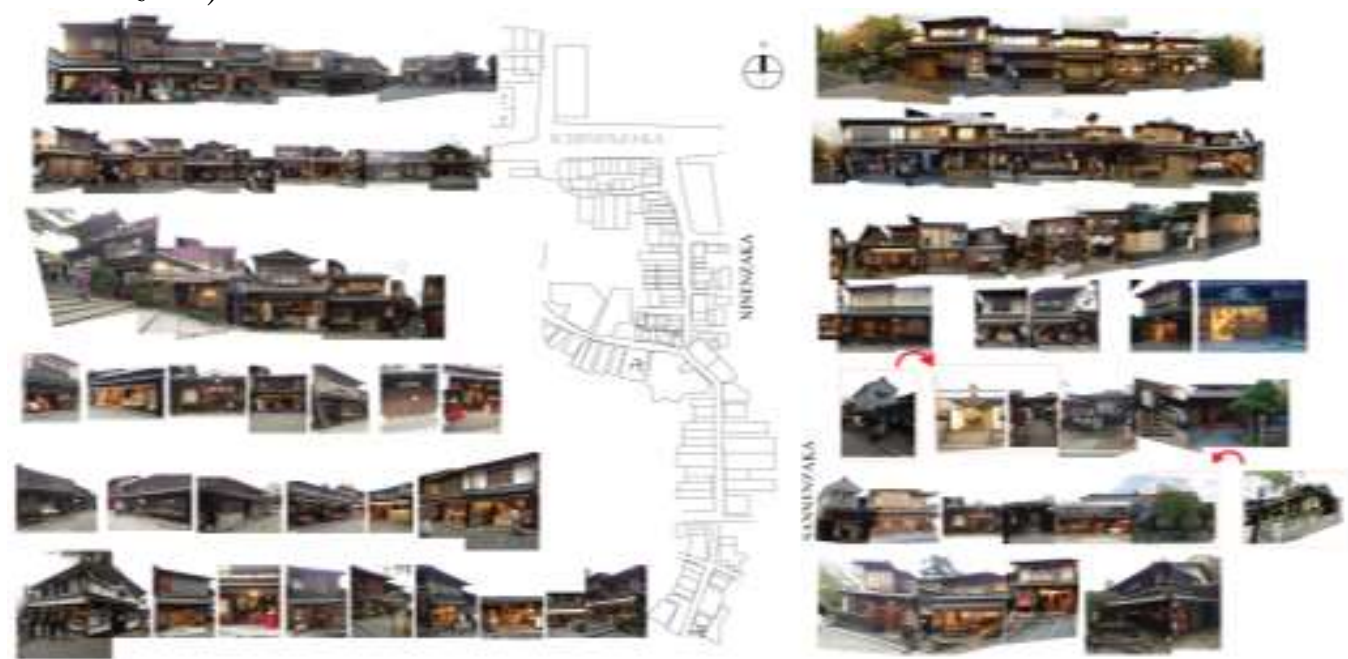

Source: On-site survey. Sep 2013 and Feb 2014. Sanneizaka and Nineizaka area. Naphasinee Suebsuk.

A field survey along the main slope of Sanneizaka and Nineizaka (Figure 2), followed the regulations, the five types of stipulated Machiya facades found in this area are: 
Machiya with mushiko or insect-cage windows in the clay walls of the suppressed second floor; these are already shown on screens depicting the town scenery of Kyoto in the Muromachi era of the sixteenth century. They can be used as dwellings or shops with dwellings (Figure 3).

Figure 3. Machiya with Mushiko or Insect-Cage Windows
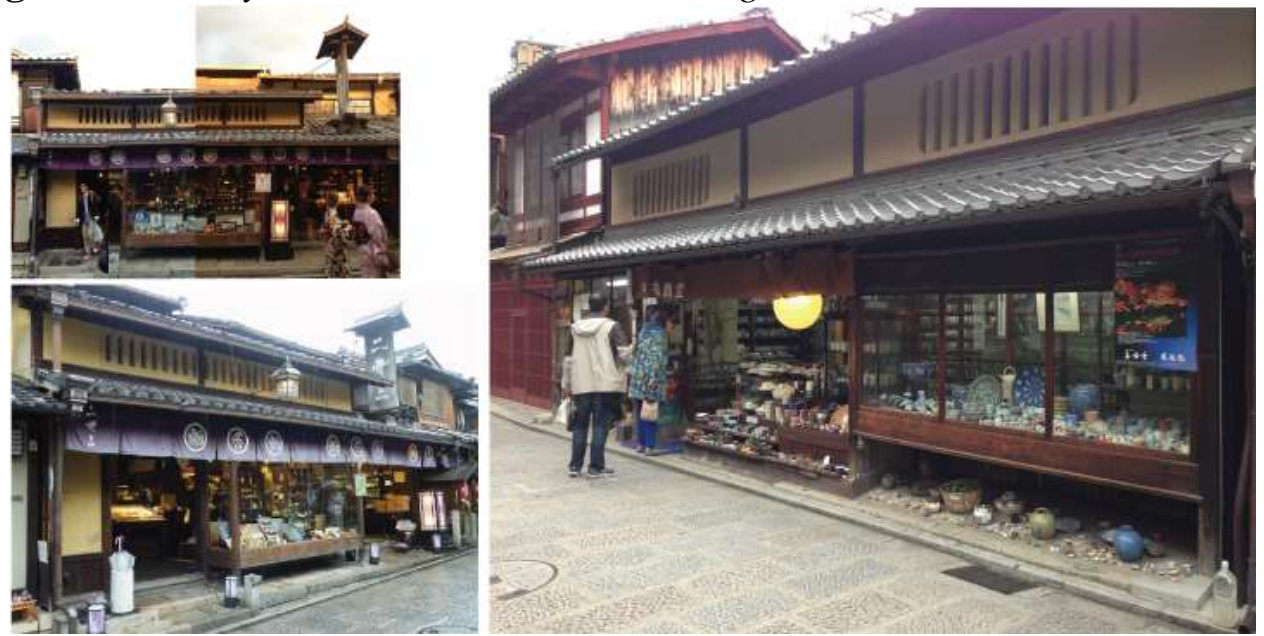

Source: On-site survey. Sep 2013 and Feb 2014. Sanneizaka and Nineizaka area. Naphasinee Suebsuk.

Two-storied Machiya from the Meiji era onwards. These show most of the characteristics of Machiya found in the area. It also has two alternatives: a dwelling and a shop with shop windows combined with a dwelling (Figure 4).

Figure 4. Two-Storied Machiya Flourishing from the Meiji Era (1868-1962) Onwards
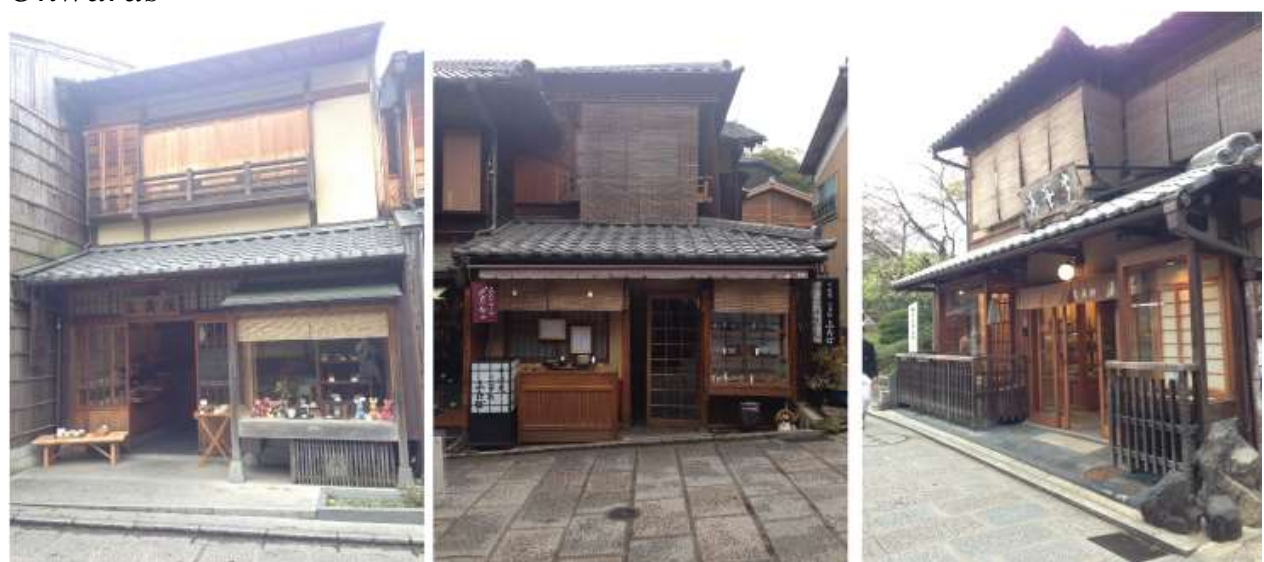

Source: On-site survey. Sep 2013 and Feb 2014. Sanneizaka and Nineizaka area. Naphasinee Suebsuk.

The modified two-storied Machiya, appearing from Taisho times (19121926) onwards; it displays just a touch of Kyoto's delicate Sukiya architecture. 
There are two types: a dwelling or a shop along with a dwelling with shop windows to the street (Figure 5).

Figure 5. The Modified Two-Storied Machiya
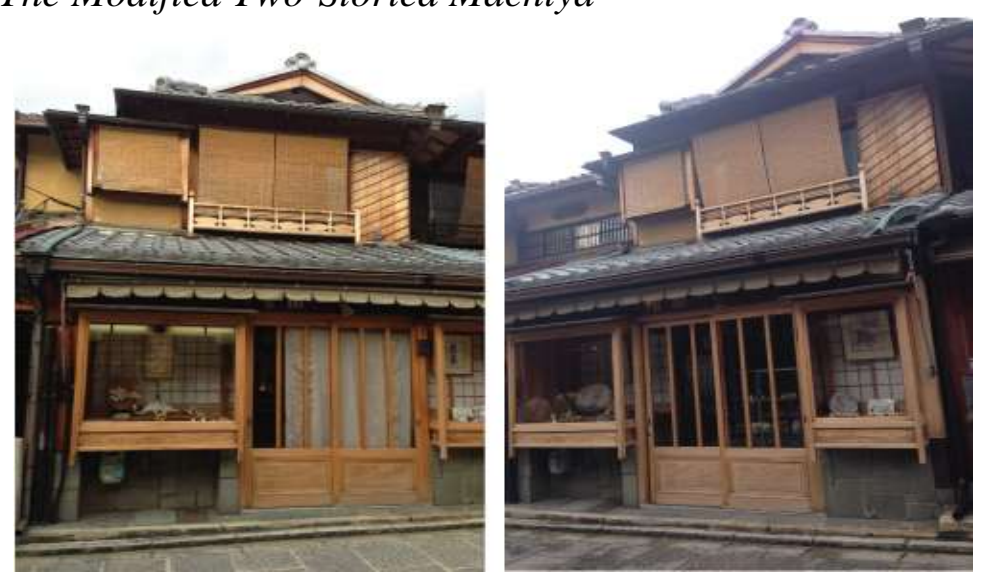

Source: On-site survey. Sep 2013 and Feb 2014. Sanneizaka and Nineizaka area. Naphasinee Suebsuk.

The Sukiya-style Machiya, designed in the spirit of wabi-sabi ${ }^{1}$ tea arbour style architecture (Figure 6).

Figure 6. The Sukiya-Style Machiya

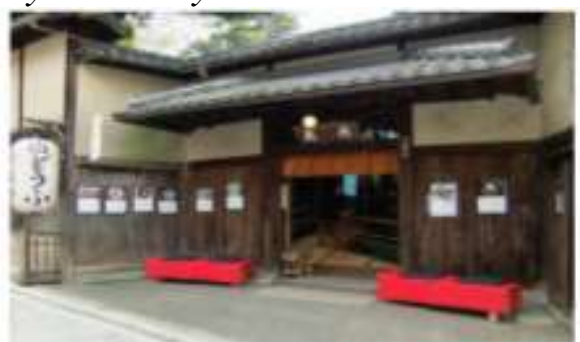

Source: On-site survey. Sep 2013 and Feb 2014. Sanneizaka and Nineizaka area. Naphasinee Suebsuk.

The other Machiya style buildings; Machiya-like buildings which are different from the four types mentioned above were built or modified in other periods (Figure 7).

\footnotetext{
${ }^{1}$ Wabi-sabi (侘寂) represents a comprehensive Japanese world view or aesthetic centred on the acceptance of transience and imperfection (Wikipedia, the encyclopedia online).
} 
Figure 7. The Others Resembling Machiya Style
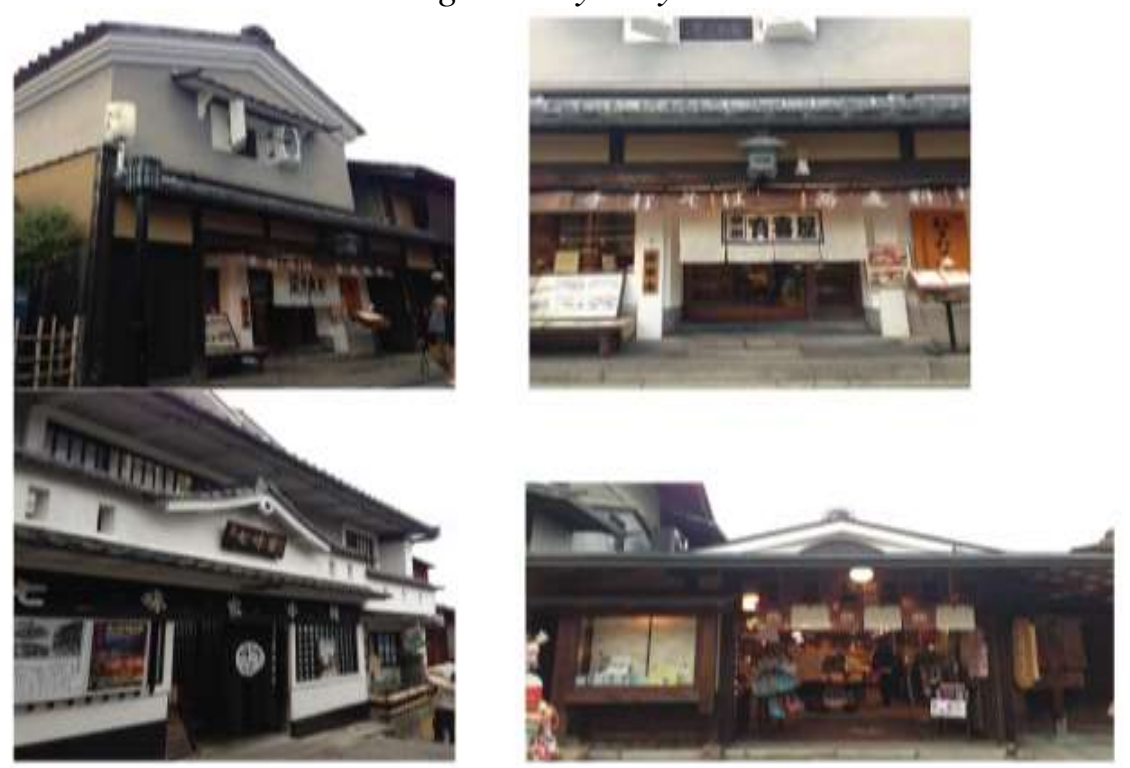

Source: On-site survey. Sep 2013 and Feb 2014. Sanneizaka and Nineizaka area. Naphasinee Suebsuk.

The Changes of Building Functions in Nineizaka and Sanneizaka from 1976 to the Present (2014)

In Sanneizaka and Nineizaka and the surrounding area, adaptive re-use has been widely used as a conservation and redevelopment tool to revive old, dilapidated buildings, and to subsequently increase their architectural, functional, and economic potential. Adaptive re-use refers to a deliberate change made in the function of a building while keeping intact the original building façade, form, and character. According to records kept by Hongii and Junzo (2001), following a survey conducted to find the transformation of land and buildings in Sanneizaka and Nineizaka and the surrounding area in 1977, 1988 and 1999, the transformation of building functions in 2014 is compared in Figure 8. This survey found an increase in the transformation of residences or dwellings into shops and even the transfer of traditional shops into new style souvenir shops (Table 1(a),(b),(c), Figure 9, Figure 10, Figure 11). The number of new shops in the area has increased as can be seen from the data collected in the interviews and questionnaires on the age of the shops in Figure 12. 
Figure 8. The Changes in Building Function of the Group of Historical Buildings in the Sanneizaka and Nineizaka Area in 1977, 1988, 1999 and the Present 2014
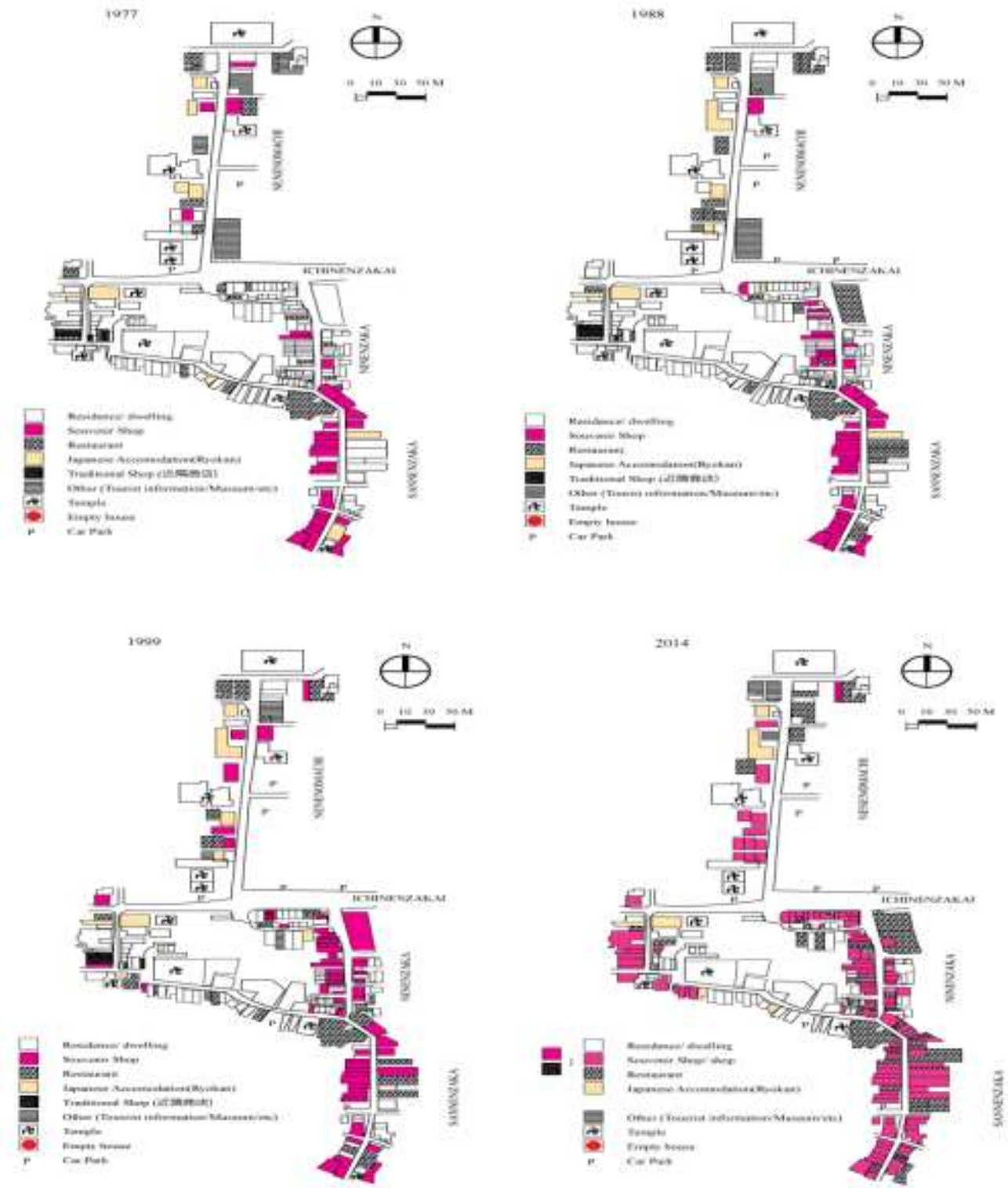

Source: Hongii and Junzo. 2001 \& On-site survey. Sanneizaka and Nineizaka area. Sep 2013 and Feb 2014. Naphasinee Suebsuk. 
Table 1 (a), (b), (c). The Tables Show the Building Function Changes from 1977 to 1988,1988 to 1999 and 1999 to 2014

\begin{tabular}{|c|c|c|}
\hline \multicolumn{3}{|l|}{ (a) } \\
\hline 1977 & 1988 & Amount \\
\hline \multirow[t]{4}{*}{ Residence/Dwelling } & Souvinir Shop & 4 \\
\hline & Restaurant & 8 \\
\hline & Ryokan & 1 \\
\hline & Others & 3 \\
\hline \multirow[t]{2}{*}{ Souvinir } & Residence & 1 \\
\hline & Restaurant & 3 \\
\hline \multirow[t]{2}{*}{ Restaurant } & Residence & 2 \\
\hline & Souvinir Shop & 1 \\
\hline \multirow[t]{2}{*}{ Ryokan } & Residence & 3 \\
\hline & Restaurant & 2 \\
\hline \multirow[t]{2}{*}{ Traditional Shop } & Residence & 1 \\
\hline & Souvinir Shop & 1 \\
\hline \multirow[t]{3}{*}{ Others } & Residence & 2 \\
\hline & Souvinir Shop & 1 \\
\hline & Restaurant & 2 \\
\hline \multicolumn{2}{|l|}{ Sum } & 35 \\
\hline \multicolumn{3}{|l|}{ (b) } \\
\hline 1988 & 1999 & Amount \\
\hline \multirow[t]{2}{*}{ Residence/Dwelling } & Souvinir Shop & 11 \\
\hline & Restaurant & 8 \\
\hline Souvinir & Residence & 2 \\
\hline \multirow[t]{2}{*}{ Restaurant } & Souvinir Shop & 8 \\
\hline & Ryokan & 1 \\
\hline Ryokan & Restaurant & 1 \\
\hline Traditional Shop & Souvinir Shop & 1 \\
\hline Others & Residence & 2 \\
\hline \multicolumn{2}{|l|}{ Sum } & 34 \\
\hline \multicolumn{3}{|l|}{ (c) } \\
\hline 1999 & 2014 & Amount \\
\hline Residence/Dwelling & Souvinir Shop & 4 \\
\hline Souvinir & Residence & 1 \\
\hline \multirow[t]{2}{*}{ Restaurant } & Souvenir Shop & 10 \\
\hline & Ryokan & 1 \\
\hline Ryokan & Restaurant & 3 \\
\hline Traditional Shop & Souvinir Shop & 18 \\
\hline Others & Ryokan & 1 \\
\hline Sum & & 38 \\
\hline
\end{tabular}

Source: Hongii and Junzo, 2001 \& On-site survey and Questionnaires. Sanneizaka and Nineizaka area. Sep 2013 and Feb 2014. Naphasinee Suebsuk. 
Figure 9. Transformation of the Building Function from 1977 to 1988 (Refer to Table 1a)

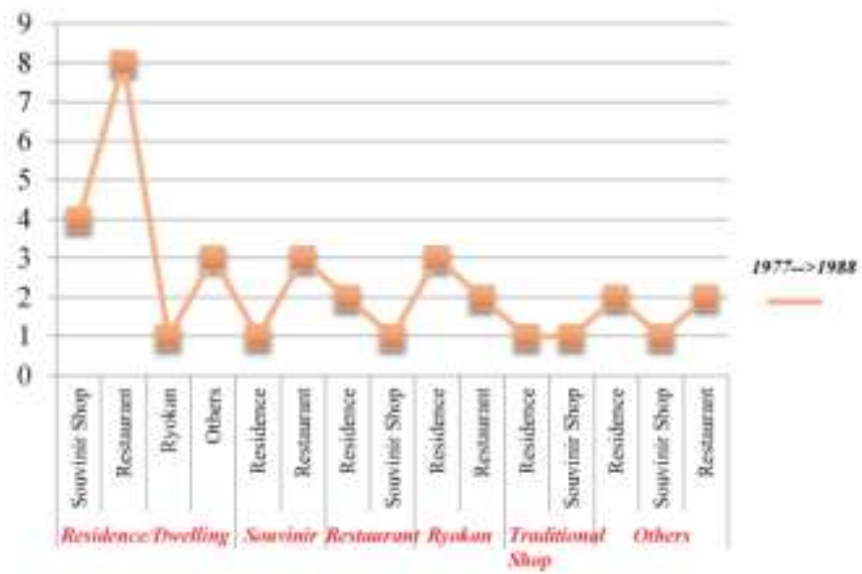

Figure 10. Transformation of the Building Function from 1988 to 1999 (Refer to Table $1 b$ )

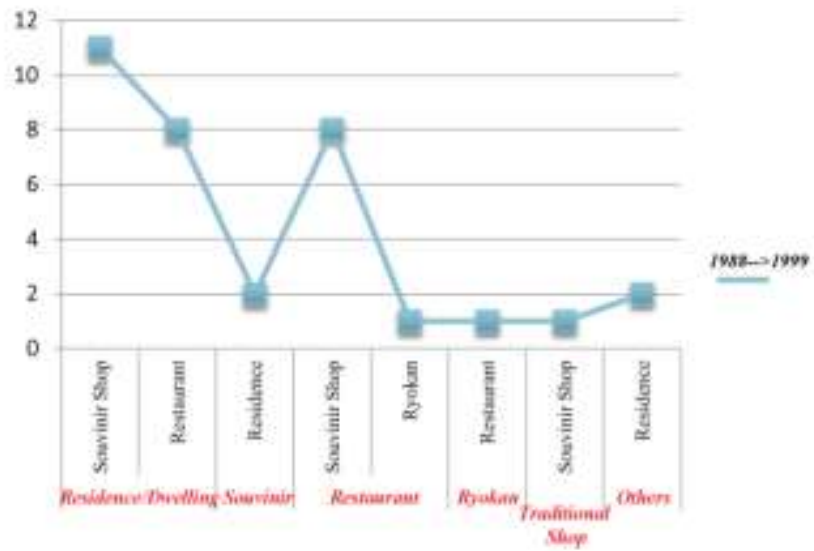

Figure 11. Transformation of the Building Function from 1999 to 2014 (Refer to Table 1c)

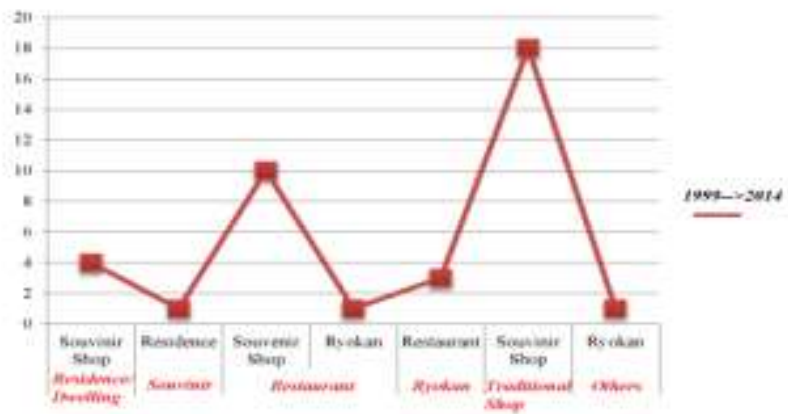


Figure 12. The Age of the Shops and Restaurants in Sanneizaka and Nineizaka in 2014
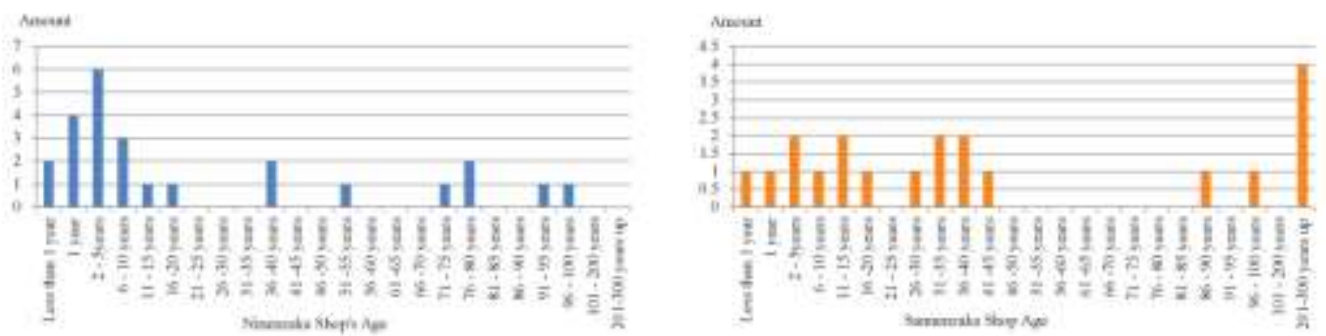

Source: Interview and Questionnaires. Sanneizaka and Nineizaka area. Sep 2013 and Feb 2014. Naphasinee Suebsuk.

As a result, the progress in commercialisation of the historical buildings increased, with a high number of residences/dwellings being transformed into souvenir shops, and traditional shops into souvenir shops since 1988 and more rapidly from 1999 through to 2014. The secondary data followed the transformation into restaurants and Ryokan (Japanese style hotel). By contrast, the original function of Machiya, where people lived in the shop, or traditional shops in the collected data, shows a huge decrease from 1999 to 2014. It found that the commercialisation of this area was largely attributable to flourishing tourism with souvenir shops, restaurants or shops selling food and drink. For an overall image, the façade of the building can retain the townscape and outdoor image in Kyoto Machiya style and various interior styles show that the tourist-oriented design performs a more traditional function than in the past (Figure 13)

Figure 13. Various Styles of the Shop Interior

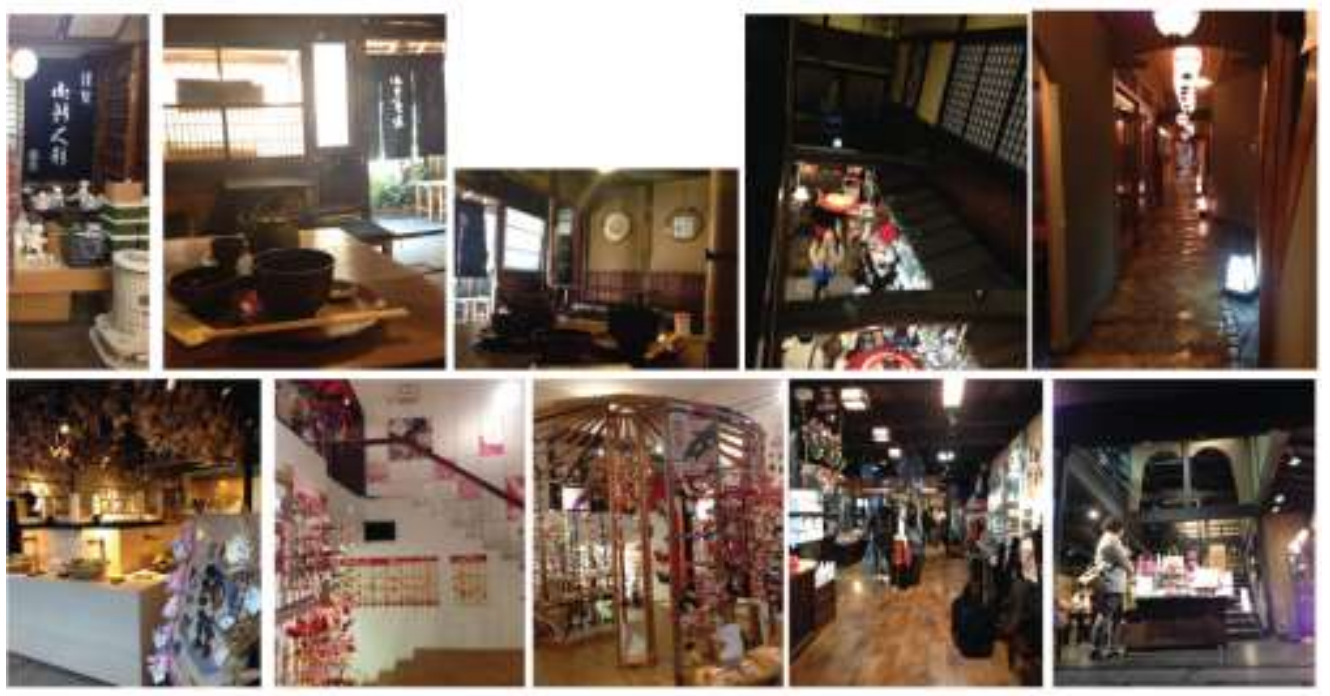

Source: Interview and Questionnaires. Sanneizaka and Nineizaka area. Sep 2013 and Feb 2014. Naphasinee Suebsuk. 
Owners' Rights of Urban Conservation for the Group of Historical Buildings in the Sanneizaka and Nineizaka Preservation District

Data from the interviews and questionnaires (Table 2, Table 3) depict the building owner's rights. Instead of inheritance or transfer from generation to generation, most of the building rights have changed into the rent/hire and sale of property by the formal owner. From the interviews, the advancing age of the formal owner, economic growth and tourism in the area, arrival of globalization, and need for a new lifestyle are the main reasons for the change.

Table 2. Owners' Rights to Buildings in the Nineizaka Area

\begin{tabular}{|l|c|c|c|}
\hline \multirow{4}{*}{ Nineizaka } & Owners' right by & Amount & $\%$ \\
\cline { 2 - 4 } & Inherit/Receive & 4 & 16 \\
\cline { 2 - 4 } & By Purchase & 5 & 25 \\
\cline { 2 - 4 } & N/A & 6 & 30 \\
\cline { 2 - 4 } & Rent/Hire & 10 & 50 \\
\hline Sum & 25 & 100 \\
\hline
\end{tabular}

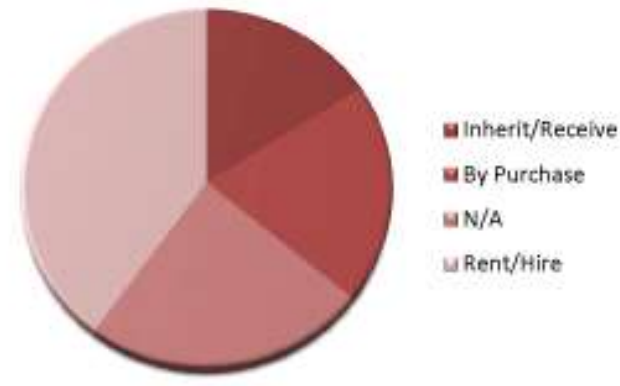

Nineizaka Building Ownership pattern

Table 3. Owners' Rights to Buildings in the Sanneizaka Area

\begin{tabular}{|l|c|c|c|}
\hline \multirow{4}{*}{ Sanneizaka } & Owners' right by & Amount & $\%$ \\
\cline { 2 - 4 } & Inherit/Receive & 8 & 40 \\
\cline { 2 - 4 } & By Purchase & 4 & 20 \\
\cline { 2 - 4 } & Rent/Hire & 8 & 40 \\
\hline Sum & 20 & 100 \\
\hline
\end{tabular}

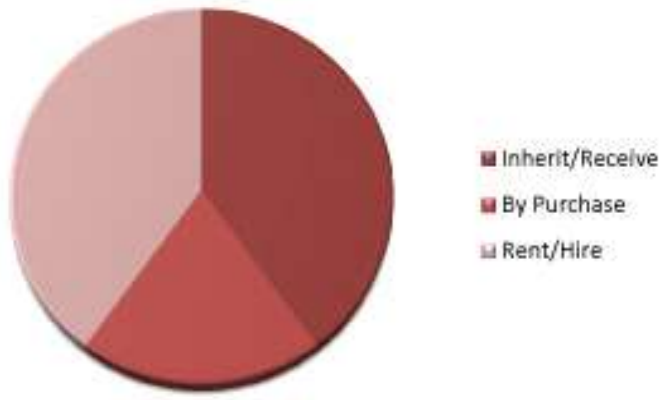

Sanneizaka Building Ownership pattern 
Building users' and shop owners' opinions on urban restoration and conservation changes for the group of historical buildings in the Sanneizaka and Nineizaka Preservation District

The opinions of the building users and shop owners regarding the changes after the area became controlled by the Preservation District regulations in 1976 (Table 4) are as follows: $32 \%$ of those interviewed answered that the changes bring a lot of guests or tourists to the area and increase its popularity with promotion in magazines and the media. However, $28 \%$ said it is hard to maintain the preservation regulations, following an increase in the property sold, problems with waste increase on the road, an increase in value of the place, and the loss of architectural design. Some of the building users cannot answer this question since their shops have only been open for a few years.

In Table 5, most of the building users and shop owners agree with the Kyoto Rashii or Kyotoishness impression of the area (76\%), followed by those who thought the shop should be suited to the place (48\%) and show awareness in retaining the "originality" or "authenticity" of the people in the area. Though there is a percentage that place more value on economics than sustainability. The maintenance required can place pressure on businesses and the effect of keeping the original features can bring more guests or tourists to the area.

Table 6 shows that about $80 \%$ of the users and shop owners want to keep only the original façade, $8 \%$ want to keep part of the house as before, and $8 \%$ thought that the original parts may not remain but only want to keep the design that represents the past.

Table 4. The Opinions of Building Owners and Users in the Sanneizaka and Nineizaka Area on the Changes Regarding the Preservation District Since 1976

\begin{tabular}{|l|c|c|}
\hline Changes in the place or area regarding the Preservation District since 1976 & $\%$ \\
\hline Owner/User's opinion & 8 from 25 & 32 \\
\hline Brings a lot of guests to the place & 3 from 25 & 12 \\
\hline The sold amount increases & 3 from 25 & 12 \\
\hline Waste increase on the road bringing problems & 7 from 25 & 28 \\
\hline It's hard to keep the preservation Regulation & 0 & 0 \\
\hline Renovation costs /Maintenance costs support increase & 2 from 25 & 8 \\
\hline Increase value of the place & 8 from 25 & 32 \\
\hline Place was promoted in magazines and media & 7 from 25 & 28 \\
\hline Neighbourhoods of the past become fewer & 2 from 25 & 8 \\
\hline The appearance of architecture design in the past is lost
\end{tabular}

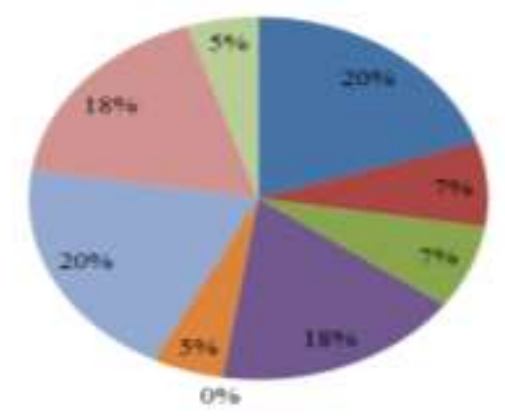

= Bring a loe of guests to the place

- The sold amount increase

W Waste increase on the road that brought the problem

- It 's hard to keep the preservation Regulation

m Renovatiou conts / Maintenance

coats suportation inctease

s Increase value of the place 
Table 5. The Opinions of Building Owners and Users in the Sanneizaka and Nineizaka Area on the Effect of Keeping the "Original" "Traditional" and "Authenticity"

\begin{tabular}{|l|c|c|}
\hline $\begin{array}{l}\text { The opinions on the effects of keeping the "Original" "Traditional" and "Authenticity" } \\
\text { of the place/house }\end{array}$ & $\%$ \\
\hline Owner/User's opinion & 4 from 25 & 16 \\
\hline Brings a lot of guests to the place & 12 from 25 & 48 \\
\hline Suitable for the type of shop or restaurant & 19 from 25 & 76 \\
\hline "Kyoto Rashi" "Kyotoishness" impression & 1 from 25 & 4 \\
\hline The maintenance of the place brings pressure on the business
\end{tabular}

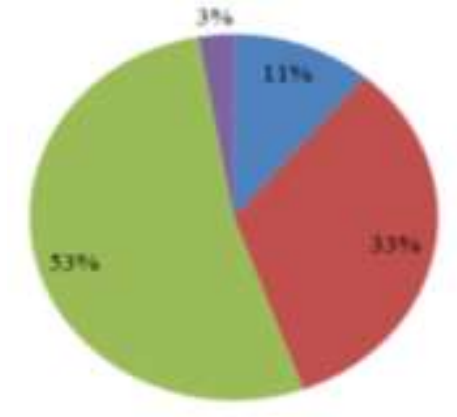

- Bring a loe of kuests to the place

- Sutable for the bope of abop or restaurant

" "Kyoto Rashi" 'Kyotoinhnew" impresaion

- The Mainsenance of the place

brings the presure on the buaines

Table 6. The Expectation of Building Owners and Users in the Sanneizaka and Nineizaka Area on Reparation or Restoration of the Historical Buildings

\begin{tabular}{l|c|c|}
\hline $\begin{array}{l}\text { If there was a reparation or restoration, which part would you expect to keep as } \\
\text { original? }\end{array}$ & $\%$ \\
\hline Owner/ User's opinion & 20 from 25 & 80 \\
\hline Want to keep the original Façade/Exterior & 2 from 25 & 8 \\
\hline Want to keep the part of the house as before & 2 from 25 & 8 \\
\hline $\begin{array}{l}\text { Original part may not remain but want to keep the design that } \\
\text { represents the past }\end{array}$ &
\end{tabular}
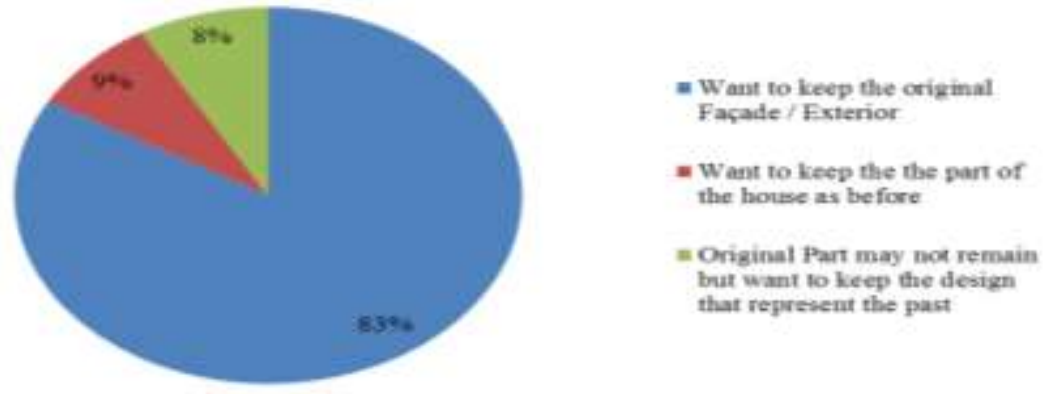

The rapid growth of tourist industry business is reflected in the social transformation as described in the data above. Changes in the employment structure and rapid transfer of owners' rights, also affects the motivation of building users and shop owners in their awareness of traditional activity. Actually, the city makes an effort to conserve, revitalise, and create an urban landscape suitable for each local characteristic. This is only achieved by setting building design standards based on the Landscape Act and Kyoto City Ordinance on Development of Urban Landscape. Strong attempts need to be 
made to create industry based on the context of local activity, and tourism related activities should play a part in conveying local appeal to visitors and enabling the way of life in the original culture of the site to be perpetuated.

In summary, from the data collected, there is a tendency towards attracting temporary users or residents to the area. There is an increase in the number of new shops (including souvenir shops) and reflects a change in values and lifestyle. Economics and efficiency are driven less by the motivation of the internal structure of local appeal, including a wide growth in leisure time and income, a rise in the age of the population, changes in the employment structure, and the decrease in transportation time and costs. These can also be seen as a phenomenon of globalization in the Sanneizaka and Nineizaka Preservation District. These changes may have generated an impact in socioeconomic, geographical, political, and technical areas and have also affected tourist behaviour and taste which in turn affect the original culture of the area regarding demand and supply. It is these forces which have influenced the tendency to change in building use, ownership transfer, or even the character of the traditional shop in the Sanneizaka and Nineizaka area.

\section{Conclusions}

The urban attraction of the buildings in this area are blended together in quite different styles, sizes, textures, uses and colours of the houses, originating from different historic periods and their intrinsic architectural styles. Under the regulations to protect townscapes, this scenario is projected to the attentive visitor as they walk along the winding, sloping path, as if in the setting of an old picture. It could be inferred that the concrete outdoor experience of the Sanneizaka and Nineizaka Preservation District is a classic example of a time, motion, and emotional structure.

However, from the data collection, the continuous changes to building function, and the transfer of owner's rights, show a trend towards sustainable tourism since 1988; increasing rapidly in the last decade. These highly interconnected urban challenges hinder the sustainable social progress of the area and the environmental development (both built and natural), which shows a typical urban transformation phase in terms of internal structure, dominated by the threat to sustainability of social development and tourism.

The effect of sustainable tourism consumption can be seen in the commuting habits of urban residents. The resulting internal structure transformation can be attributed to land use development patterns building awareness for local people to pass on to later generations. This represents the context in which the city is attempting to make progress towards sustainability.

More effective interventions are also required in terms of modern facility consumption, freedom for elders, and disaster protection. It is necessary that legislation makes provision for higher levels of government to override lower levels, in order to rectify shortcomings or address particular problem areas. 
In order to maintain and sustainably develop excellent landscapes, not only in the regulations, it is very important to deepen people's understanding of the importance of landscape and to train those who can engage in the creation of landscape in the future. It is necessary for the city to take action to achieve these purposes.

Kyoto is a large historical city inhabited by a growing population. It is blessed with exquisite traditional and advanced industries. With this in mind, Kyoto has to achieve a balance between the conservation and revitalisation of its landscape and various other city policies. Meanwhile, a sustainable urban transformation monitoring system needs to be established in the city. The selected indicators need to be aligned with international indicators, which can help to set up relevant and appropriate benchmarks that may lead to the urban transformation of the city towards being more people-oriented in the sustainable future. Under this framework, information and data must be collected.

Good landscaping will add to the value and charm of the city and attract a greater number of residents and tourists. As a result, skilled people will gather and investment in local industry, tourism, and knowledge will also increase in Kyoto.

Moreover, the ageing population, length of residence of shop owners or building users, showed an influence in their perception of preservation and conservation awareness in urban sustainable development that needs to be reconsidered for further generations of building user.

The various processes of urban transformation have long term implications. It is impossible to plan for the needs of the next ten to twenty years without more accurate data from which trends such as tourism growth, community demands, and infrastructure requirements can be determined. Obtaining the correct data is therefore one of the main recommendations to the municipal government.

Hereafter, it is believed that some of the effects of this transformation can be evaluated by investigating the business categories, shop owners or building users to create some methodology for application not only to the special preservation area, but also extensively with respect to other historical places and those attempting to promote sustainable tourism.

\section{Acknowledgements}

Our gratitude to all interviewees, respondents, members of Nakagawa Laboratory, Department of Architecture and Design, Kyoto Institute of Technology for research collection and preparation processes during the research. S. Naphasinee wishes to thank friend and professor in Nakagawa Laboratory, Department of Architecture, Kyoto Institute of Technology, for the translation of the on-site survey questionnaire into the proper Japanese language; bringing greater reliability to the research. Thanks to the Kato Asao 
Foundation for the Scholarship to support part of the research expenses and to all family and friends for their encouragement in this research.

\section{References}

Barnett J (1974) Urban Design as Public Policy. New York: Architectural Record Books.

Graburn NHH (1995) The Past in the Present in Japan: Nostagia and NeoTraditionalism in Contemporary Japanese Domestic Tourism. In: R Butler and D Peace (eds) Change of Tourism: People, Places, Processes. London: Routledge. 47-68.

Hongii K and Junzo M (2001) A Study on The Relationship between the change in Building use and Ownership Transfer in Sanneizaka Preservation District for Groups of Historical Buildings. Journal of Architectural Planning and Environment 545(July): 215-221. (in Japanese).

Kyoto Center for community Collaboration (2009) Machiya Revival in Kyoto. Kyoto, Japan: Mitsumura Suiko Shoin Publishing Co., Ltd.: 13-43.

Salastie R (1989) A description of the four historic preservation areas. Kioton historialliset puutaloalueet (The Historic Wooden Town Areas of Kyoto). In: Puu (Finnish Wood Magazine) 1-2/1990. Helsinki: Helsinki University of Technology. 126-139. 